\title{
Pooled specimens for Chlamydia trachomatis: new approach to increase yield and cost efficiency
}

\author{
A R G MANUEL,* M VEERAVAHU,* R S MATTHEWS, $\uparrow$ AND J C CLAY* \\ From the ${ }^{*}$ Department of Genitourinary Medicine, General Hospital, and the $\dagger$ Department of Microbiology, \\ Dudley Road Hospital, Birmingham
}

SUMMARY Pooled specimens from the urethra and cervix accounted for $97 \%$ of 101 positive chlamydial isolations in 332 women, and this yield compared favourably with the individual yield from either the urethra $(77 \%)$ or the cervix $(88 \%)$. Pooling specimens caused no apparent increase in toxicity to the cell culture system. These results indicate the advantages, in terms of higher yield and no higher cost, of combining the urethral and cervical specimens in one container.

\section{Introduction}

Despite refinements in laboratory procedures for the isolation of Chlamydia trachomatis, the collection of specimens remains an important factor influencing ultimate yields. The intracellular location of the organism means that a good harvest of epithelial cells is necessary to ensure acceptable results. ${ }^{1}$

Workers have claimed substantial increases in the numbers of diagnoses of female genital tract infections after multiple site testing. ${ }^{2}$ This approach, however, increases the cost of an investigation whose availability is already severely restricted by cost (because the cell culture methods used are labour intensive ). It is therefore surprising that studies of the potential advantages of processing pooled specimens from different sites have not been published.

In theory, a pooled specimen from the urethra and cervix might be expected to yield as much information as two separate specimens but at half the cost. The increased number of infectious particles in the pooled specimen might even result in an increased overall yield. Alternatively, enhanced toxicity to the cell culture system might make this method counterproductive. We therefore designed this study to explore these possibilities.

\section{Patients, materials, and methods}

The study was performed on new and returning women

Address for reprints: Dr J C Clay, Ward 19, General Hospital, Birmingham B4 6NH

Accepted for publication 24 September 1986. patients attending the sexually transmitted disease (STD) clinic at the General Hospital, Birmingham, from May 1985 to April 1986. The following women were excluded from the study: those who had taken antibiotics in the previous four weeks, were prepubertal, postmenopausal, or pregnant, or who had undergone hysterectomy. Informed consent was obtained from all the patients included in the study, and they were examined by one author only (ARGM). The samples were taken in the sequence shown in table I.

TABLE I Sequence of samples taken from and tests performed for each patient

\begin{tabular}{|c|c|c|}
\hline 1 & Urethra & $\begin{array}{r}\text { - Gram film and culture for Neisseria gonorrhoeae } \\
\text { - Culture for Chlamydia trachomatis (individual } \\
\text { specimen or pooled with specimen from cervix }{ }^{*} \text { ) }\end{array}$ \\
\hline & Cervix & $\begin{array}{l}\text { - Exfoliative cytology } \\
\text { - Gram film and culture for } N \text { gonorrhoeae }\end{array}$ \\
\hline & Vagina & $\begin{array}{l}\text { - Gram film } \\
\text { - Wet film and culture for Trichomonas vaginalis } \\
\text { - Amine and pH tests }\end{array}$ \\
\hline & Cervix & $\begin{array}{l}\text { - Culture for } C \text { trachomatis (second individual } \\
\text { specimen or pooled with specimen from } \\
\text { urethra*) }\end{array}$ \\
\hline & Rectum & Culture for $N$ gonorrhoeae \\
\hline & Pharynx & Culture for $\boldsymbol{N}$ gonorrhoeae (if fellatio practised) \\
\hline & Urine & Urine analysis (N-Multistix) \\
\hline & Blood & Serological tests for syphilis \\
\hline & Ulcers & $\begin{array}{l}\text { - Culture for herpes simplex virus } \\
\text { - Dark ground microscopy }\end{array}$ \\
\hline
\end{tabular}

* Randomisation code decided order in which urethral and cervical specimens were first tested individually or together. 
SPECIMENS FOR C TRACHOMATIS

Each patient was assigned a randomisation code that was used to decide which swab was to be placed first in the individual or pooled specimen container (fig 1). The urethral meatus was first wiped with a cotton wool ball soaked in saline. A sterile cotton tipped wooden swab moistened in the transport medium was then inserted into the urethra, rotated gently against the mucosa, and placed in the transport medium. The cervix was wiped with a dry cotton wool ball. A sterile cotton tipped wooden swab was then inserted into the endocervical canal, rotated against its wall a few times, and placed in the appropriate container.

\section{Storage and transport of specimens}

All chlamydial swabs were broken off into glass containers with $2 \mathrm{ml}$ of the transport medium and stored at $4^{\circ} \mathrm{C}$ for less than 24 hours before inoculation. The transport medium was Eagle's minimum essential medium with Earle's salts, vitamins, non-essential amino acids, and $10 \%$ fetal calf serum.

\section{Isolation method}

After the transport medium was agitated on a vortex mixer, $1 \mathrm{ml}$ was inoculated on to a monolayer of McCoy cells pretreated with 5-iodo-2'-deoxyuridine and grown on the flat base of a $16 \times 100 \mathrm{~mm}$ glass tube. The monolayer tubes were centrifuged at 2000 RCF (relative centrifugal force) for one hour and incubated at $35^{\circ} \mathrm{C}$ for 48 hours. The presence or absence of chlamydial inclusions was shown by a fluorescence technique developed in this laboratory.

After the tissue monolayer had been washed carefully in phosphate buffered saline (PBS), the cells were scraped into the PBS residue and into $3 \mathrm{~mm}$ wells on a poly-tetra-fluo-ethylene (PTFE) multislide, allowed to air dry, and fixed in cold acetone. A volume of $4 \mu \mathrm{l}$ of monoclonal antisera (Boots Celltech) was pipetted into each well. The slides were incubated for 30 minutes at $37^{\circ} \mathrm{C}$, washed in PBS for five minutes, and

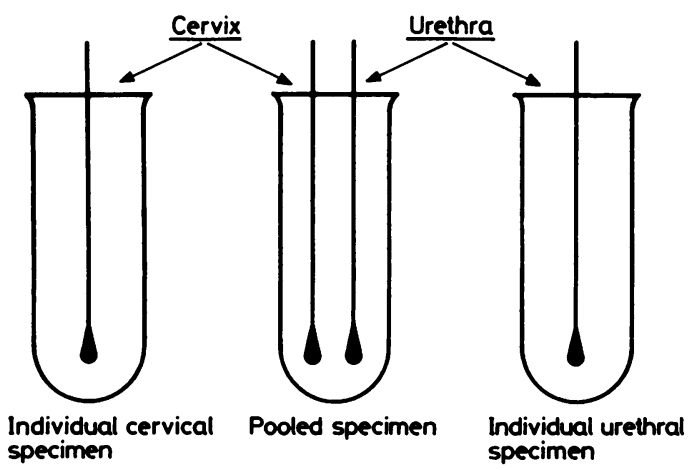

FIG 1 Definition of specimens taken from urethra and cervix mounted in glycerol saline. We subcultured any tissue cultures that were unsuitable for microscopy because of a toxic effect or other factors.

\section{CULTURE FOR NEISSERIA GONORRHOEAE}

Urethral, cervical, vaginal, and rectal swabs were inoculated on to Birmingham General Hospital vancomycin, colistin, and trimethoprim (VCT) medium and cultured as described previously. ${ }^{3}$

McNemar's test was used to compare the yields from individual and pooled specimens. ${ }^{4}$

\section{Results}

Of the 345 women examined, 13 were excluded from the study because of alkaline changes in the transport medium, disruption of the cell culture with Trichomonas vaginalis or herpes simplex virus, or labelling errors. C trachomatis was isolated from 101 $(30 \%)$ of the remaining 332 women.

Figure 2 shows the yield from the individual and pooled specimens. $C$ trachomatis was isolated from $98(97 \%)$ pooled specimens compared with $89(88 \%)$ single specimens from the cervix and $78(77 \%)$ single specimens from the urethra. There were significant differences between the isolation rates from the pooled specimens compared with rates from single specimens from the cervix $(p<0.05)$ and the urethra $(p<0.001)$. Cultures were positive in $57(34 \%)$ cases when pooled specimens were taken first and in 44 (27\%) when single specimens were taken first. The difference was not significant.

$T$ vaginalis was isolated from the chlamydial culture specimens from 4\% (12/336) of women. By seeding the chlamydial specimens on to human embryo lung cells in separate tubes, herpes simplex virus was isolated from $3 \%(10 / 336)$ and cytomegalovirus from $2 \%(6 / 336)$ of women.

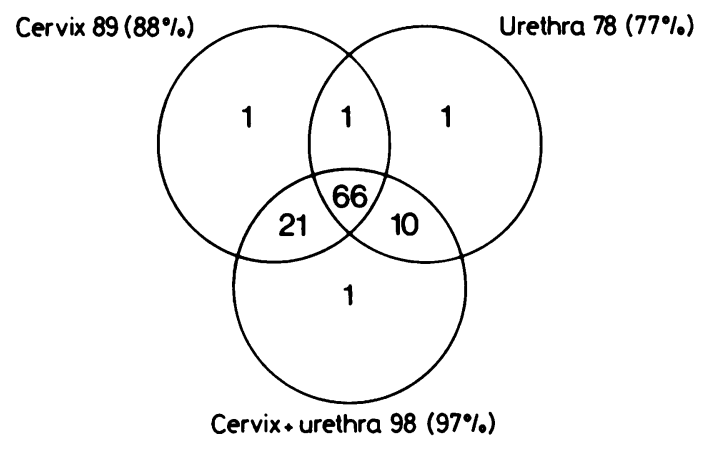

FIG 2 Isolation of Chlamydia trachomatis from individual cervical and urethral specimens and pooled specimens from 101 women 
C trachomatis was isolated from $30 / 48(63 \%)$ of women who were consorts of men with gonorrhoea and $28 / 58(48 \%)$ of those whose sexual partners had nongonococcal urethritis. Of the remaining 226 women, 43 (19\%) gave positive results. $C$ trachomatis was also isolated from 34 of the 59 (58\%) women with coexistent culture proved gonorrhoea.

\section{Discussion}

A significantly higher yield was obtained from the pooled specimens $(97 \%)$ than from specimens from the cervix only $(88 \%)(p<0.05)$ at no extra cost. Chlamydial isolation from over $30 \%$ of women attending STD clinics has been reported by only a few workers. ${ }^{5-7}$ Our yield of $30.4 \%$ thus compares favourably with their studies and indicates the high sensitivity of the isolation method used in our study.

Dunlop et al isolated $C$ trachomatis from $73 \%$ of women with a first swab, an additional $17 \%$ with a second swab, and $10 \%$ with a third. ${ }^{8}$ They therefore suggested that two consecutive cervical swabs were preferable to a swab each from urethra and cervix, if facilities were available to take two chlamydial cultures per patients. Despite this, Munday et al suggested that the lower sensitivity of the isolation method used by Dunlop et al might have been responsible for the differences in the yield from consecutive cervical swabs. ${ }^{6}$ In our study we took two consecutive specimens from the urethra and cervix of each woman and did not find any significant differences in yield, whatever the order of taking the swabs. Furthermore, Dunlop et al attributed the increased efficiency of the last two swabs to the cleaning effect of the first swab, which removed mucus from the cervix. ${ }^{8}$ We performed cervical cytology before taking chlamydial swabs, which according to Mardh et al might have cleaned the cervix. ${ }^{9}$ Mucus was therefore unlikely to have interfered with our results. The higher yield from the pooled specimens also indicated that toxicity to the cell layer was not increased by pooling the urethral and cervical swabs.

Paavonen isolated $C$ trachomatis from the urethra only in $25 \%$ of 99 women who were consorts of men with non-gonococcal urethritis. ${ }^{2}$ This higher urethral isolation rate was explained by Bradley et al as probably being due to the relatively lower rate of isolation from the cervix (75\%) found by Paavonen. ${ }^{7}$ Table II shows that other workers (except Johannisson et $\left.a l^{10}\right)$ isolated $C$ trachomatis from the urethra alone in only $1-8 \%$ of women.27810-12 Though Bump and Copeland failed to isolate $C$ trachomatis from the urethra of 86 women with chronic urological complaints, ${ }^{13}$ Stamm et al showed the possible role of this organism in the aetiology of "urethral syndrome" in women. Nevertheless, some workers believe that the
TABLE II No (\%) of patients yielding Chlamydia trachomatis from urethra, cervix, or both

\begin{tabular}{|c|c|c|c|c|}
\hline Publications & $\begin{array}{l}\text { Urethra } \\
\text { only }\end{array}$ & $\begin{array}{l}\text { Cervix } \\
\text { only }\end{array}$ & Both & Total \\
\hline 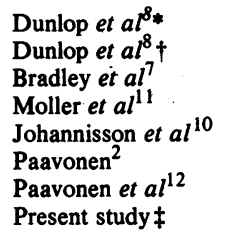 & $\begin{aligned} & 6(9) \\
& 1(1) \\
& 5(4) \\
& 2(5) \\
& 19(15) \\
& 25(25) \\
& 2(7) \\
& 11(11)\end{aligned}$ & $\begin{array}{l}43(61) \\
79(71) \\
44(38) \\
15(41) \\
75(61) \\
28(28) \\
13(48) \\
22(22)\end{array}$ & $\begin{array}{l}22(31) \\
31(28) \\
66(57) \\
20(54) \\
29(24) \\
46(47) \\
12(44) \\
67(67)\end{array}$ & $\begin{array}{r}71 \\
111 \\
115 \\
37 \\
123 \\
99 \\
27 \\
100\end{array}$ \\
\hline
\end{tabular}

* Results of first culture, excluding that of a patient yielding chlamydiae from rectum only.

$\dagger$ Results of three consecutive cultures, excluding those of a patient yielding chlamydiae from rectum only.

$\ddagger$ Excluding one patient yielding chlamydiae from the pooled specimen only.

urethra is contaminated secondary to cervical infec tion and suggest that there is no indication to take urethral swabs from women. We have shown the advantages of the urethral swab, however, in terms of increased yield and cost benefit, if it is incorporated in a pooled specimen.

In conclusior, the pooling method has worked well in our hands, but we feel that any diagnostic laboratory proposing to adopt it should not do so without validating it in their own population. Furthermore, interval testing not only provides information about the reproducibility of a method, but may be necessary to detect incubating infection. It is our intention to assess further the sensitivity of our diagnostic service in this way.

We thank Dr R A Sparks for allowing us to include his patients in this study.

\section{References}

1. Evans RT, Woodland RM. Detection of chlamydiae. Br Med Bull 1983;39:181-6.

2. Paavonen J. Chlamydia trachomatis induced urethritis in female partners of men with nongonococcal urethritis. Sex Transm Dis 1979;6:69-71.

3. Metton H, Smith RW, Clay JC. Culture of Candida albicans on gonococcal and Sabouraud's media correlated with presence or absence of signs and symptoms and positive results on microscopy and cytology. Genitourin Med 1985;61:211.

4. Armitage P. Statistical methods in medical research. New York: John Wiley, 1971:126-7.

5. Hilton AL, Richmond SJ, Milne JD, Hindley F, Clarke SKR. Chlamydia $A$ in the female genital tract. British Journal of Venereal Diseases 1974;50:1-9.

6. Munday PE, Carder JM, Hanna NF, Taylor Robinson D. Is one swab enough to detect chlamydial infections of the cervix? British Journal of Venereal Diseases 1984;60:384-6.

7. Bradley MG, Hobson D, Lee N, Tait IA, Rees E. Chlamydial infections of the urethra in women. Genitourin Med 
1985;61:371-5.

8. Dunlop EMC, Goh BT, Darougar S, Woodland R. Triple culture tests for diagnosis of chlamydial infection of the female genital tract. Sex Transm Dis 1985;12:68-71.

9. Mårdh P-A, Westrom L, Colleen S, Wolner-Hanssen P. Sampling, specimen handling, and isolation techniques in the diagnosis of chlamydial and other genital infections. Sex Transm Dis 1981;8:280-5.

10. Johannisson G, Lowhagen G B, Lycke E. Genital Chlamydia trachomatis infection in women. Obstet Gynecol 1980;56: 6715.

11. Moller BR, Jorgensen AS, From E, Stenderup A. Chlamydia, mycoplasmas, ureaplasmas, and yeasts in the lower genital tract of females. Acta Obstet Gynecol Scand 1985;64:145-9.

12. Paavonen J, Saikku P, Vesterinen E, Aho K. Chlamydia trachomatis in acute salpingitis. British Journal of Medical Diseases 1979;55:203-6.

13. Bump RC, Copeland WE. Urethral isolation of the genital mycoplasmas and Chlamydia trachomatis in women with chronic urologic complaints. Am J Obstet Gynecol 1985; 152:38-41.

14. Stamm WE, Wagner KF, Amsel R, Alexander ER, Turck M, Counti GW, Holmes KK. Etiology of the acute urethral syndrome in women. $N$ Engl J Med 1980;303:409-15. 